\title{
Ventilatory Inefficiency as a Limiting Factor for Exercise in Patients With COPD
}

\author{
Iván R Caviedes MD, Iris Delgado MSc ETH, and Rodrigo Soto MD
}

\begin{abstract}
BACKGROUND: Ventilatory inefficiency increases ventilatory demand; corresponds to an abnormal increase in the ratio of minute ventilation $\left(\dot{\mathrm{V}}_{\mathrm{E}}\right)$ to $\mathrm{CO}_{2}$ production $\left(\dot{\mathrm{V}}_{\mathrm{CO}_{2}}\right)$; represents increased dead space, deregulation of respiratory control, and early lactic threshold; and is associated with expiratory flow limitation that enhances dynamic hyperinflation and may limit exercise capacity. OBJECTIVE: To evaluate the influence of ventilatory inefficiency over exercise capacity in COPD patients. METHODS: Prospective study of 35 COPD subjects with different levels of severity, in whom cardiopulmonary stress test was performed. Ventilatory inefficiency was represented by the $\dot{\mathbf{V}}_{\mathrm{E}} / \dot{\mathbf{V}}_{\mathrm{CO}_{2}}$ relation. Its influence over maximal oxygen consumption $\left(\dot{\mathbf{V}}_{\mathrm{O}_{2}}\right.$ max), power $(\mathrm{W})$, and ventilatory threshold was evaluated. Surrogate parameters of cardiac function, like oxygen pulse $\left(\dot{\mathrm{V}}_{\mathrm{O}_{2}}\right.$ /heart rate) and circulatory power $\left(\% \dot{\mathrm{V}}_{\mathrm{O}_{2}} \max \times\right.$ peak systolic pressure), were also evaluated. RESULTS: Cardiopulmonary stress test was stopped due to dyspnea with elevated $\dot{\mathrm{V}}_{\mathrm{E}}$ and marked reduction of breathing reserve. A severe increase in $\dot{\mathrm{V}}_{\mathrm{E}} / \dot{\mathrm{V}}_{\mathrm{CO}_{2}}($ mean $\pm \mathrm{SD} 35.9 \pm \mathbf{5 . 6}$ ), a decrease of $\dot{\mathrm{V}}_{\mathrm{O}_{2}} \max ($ mean \pm SD $75.2 \pm 20 \%)$, and a decrease of $\mathrm{W}($ mean \pm SD $68.6 \pm 23.3 \%)$ were demonstrated. Twenty-eight patients presented dynamic hyperinflation. Linear regression showed a reduction of $2.04 \%$ on $\dot{\mathrm{V}}_{\mathrm{O}_{2}} \max (P<.001), 2.6 \%$ on $\mathrm{W}(P<.001), 1 \%$ on $\dot{\mathrm{V}}_{\mathrm{O}_{2}}$ /heart rate $(P=.049)$, and 322.7 units on circulatory power $(P=.02)$ per each unit of increment in $\dot{\mathrm{V}}_{\mathrm{E}} / \dot{\mathrm{V}}_{\mathrm{CO}_{2}}$, respectively. CONCLUSIONS: Ventilatory inefficiency correlates with a reduction in exercise capacity in COPD patients. Including this parameter in the evaluation of exercise limitation in this patient population may mean a contribution toward the understanding of its pathophysiology. Key words: chronic obstructive pulmonary diseases; exercise; dyspnea; work of breathing; hyperinflation. [Respir Care 2012;57(4):583-589. @ 2012 Daedalus Enterprises]
\end{abstract}

\section{Introduction}

Emphasis has been placed on the importance of dynamic hyperinflation, represented by a decrease in inspiratory capacity during exercise, as the main limiting factor

\footnotetext{
Drs Caviedes and Soto are affiliated with the Servicio y Laboratorio Broncopulmonar; and Ms Delgado is affiliated with the Departamento Científico y Docente, Clínica Alemana de Santiago, Facultad de Medicina, Clínica Alemana, Universidad del Desarrollo, Santiago, Chile.
}

The authors have disclosed no conflicts of interest.

Correspondence: Iván R Caviedes MD, Servicio y Laboratorio Broncopulmonar, Clínica Alemana de Santiago, Chile, Facultad de Medicina, Clínica Alemana, Universidad del Desarrollo, Avenida Vitacura 5951, Santiago, Chile 6681920. E-mail: icaviedes@alemana.cl.

DOI: $10.4187 /$ respcare. 01342 for physical activity in patients with COPD. ${ }^{1,2}$ Theoretically, patients with greater bronchial obstruction should exhibit greater limitations in exercise; however, this does not occur in clinical practice, where patients with a lesser degree of obstruction may exhibit greater limitations. This indicates the presence of multiple mechanisms involved in the development of these limitations. In this context, the importance of ventilatory inefficiency, which increases ventilatory demand, has not yet been assessed.

Ventilatory inefficiency represents an abnormal increase in the ratio of minute ventilation $\left(\dot{\mathrm{V}}_{\mathrm{E}}\right)$ to carbon dioxide production $\left(\dot{\mathrm{V}}_{\mathrm{CO}_{2}}\right)$ (Fig. 1). It is a multi-dependent parameter that corresponds with an increased physiological dead space, poor regulation of respiratory control, and early lactic acidosis, factors that are present in COPD. This alteration enhances the ventilatory demand and respiratory rate, which, when associated with an increased expiratory resistance in COPD, results in a reduction of the time 


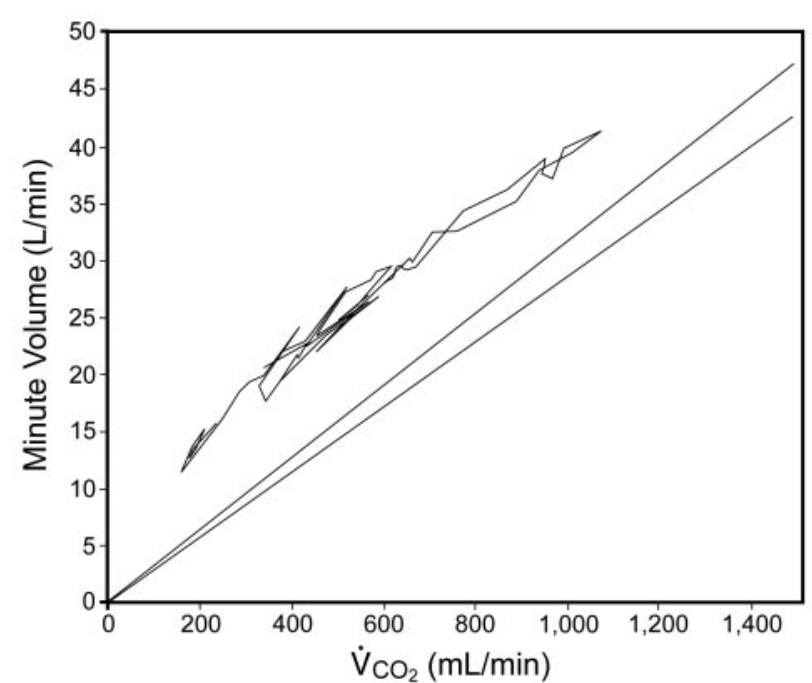

Fig. 1. A 57-year-old patient with COPD: increase in the $\mathrm{CO}_{2}$ equivalent (minute ventilation versus carbon dioxide production $\left.\left[\dot{\mathrm{V}}_{\mathrm{CO}_{2}}\right]\right)$ due to ventilatory inefficiency. The curve presents a leftward deviation, compared with a normal reference shape.

available for expiration, due to expiratory flow limitation. This mechanism impedes deflation, causes expiratory flow limitation, enhances the obstruction mechanism, and potentially cause dynamic hyperinflation. ${ }^{1,3,4}$ The greater the ventilatory demand to eliminate $\mathrm{CO}_{2}$, the greater the $\dot{\mathrm{V}}_{\mathrm{E}}$, and the greater the expiratory flow limitation and dynamic hyperinflation decreases the breathing reserve during exercise. , $^{1,3,4}$ The impact of this mechanism on the exercise capacity of patients with COPD is an antecedent that has not been evaluated, and information on the effect of these processes on cardiocirculatory function is also unavailable.

Hypothesis: Ventilatory inefficiency increases ventilatory requirement, enhancing dynamic hyperinflation when associated with expiratory flow limitation. Due to these mechanisms, ventilatory inefficiency limits exercise capacity.

Objectives: To quantify the magnitude of $\dot{\mathrm{V}}_{\mathrm{E}} / \dot{\mathrm{V}}_{\mathrm{CO}_{2}}$ measured at anaerobic threshold in patients with COPD during a cardiopulmonary exercise test (cardiopulmonary stress test), and to show that $\dot{\mathrm{V}}_{\mathrm{E}} / \dot{\mathrm{V}}_{\mathrm{CO}_{2}}$ translates into a limitation on exercise.

\section{Methods}

We performed a prospective study over 2 years in patients with mild to severe COPD, according to the Global Initiative for Chronic Obstructive Lung Disease (GOLD) criteria. ${ }^{5}$ The sample size was calculated considering $\dot{\mathrm{V}}_{\mathrm{E}} /$ $\dot{\mathrm{V}}_{\mathrm{CO}_{2}}$ as the principal variable. We used a design of mean comparison with an average difference of $20 \%$ with respect to the normal value of $\dot{\mathrm{V}}_{\mathrm{E}} / \dot{\mathrm{V}}_{\mathrm{CO}_{2}}$. The minimal esti-

\section{QUICK LOOK}

\section{Current knowledge}

Ventilatory inefficiency increases the ratio of minute ventilation to $\mathrm{CO}_{2}$ production $\left(\dot{\mathrm{V}}_{\mathrm{E}} / \dot{\mathrm{V}}_{\mathrm{CO}_{2}}\right)$ and ventilatory demand. In association with expiratory flow limitation, ventilatory inefficiency causes dynamic hyperinflation and impacts exercise capacity.

\section{What this paper contributes to our knowledge}

A large increase in $\dot{\mathrm{V}}_{\mathrm{E}} / \dot{\mathrm{V}}_{\mathrm{CO}_{2}}$ is inversely related with a reduction in oxygen consumption and power. Ventilatory inefficiency correlates with a reduction in exercise capacity in patients with COPD.

mated sample was 33 patients. For the estimation we used the following suppositions: CI of $95 \%$, and power of $99 \%$ ( $B$ error of $10 \%$ ), and one standard deviation of $25 \%$ with respect to the mean of both samples.

All participants met the following entry criteria: pulmonary emphysema by axial computed tomography. The radiological criteria were: well defined 1-2 mm centrilobular holes in the secondary pulmonary lobule with no discernible wall, preserved anatomical borders of the secondary pulmonary lobule, and involvement predominantly in the upper lung zones. ${ }^{6}$ All participants were in a nonacute phase of their disease and were receiving a stable drug regimen. Participants had no coexisting medical conditions that would interfere with physiologic testing. Exclusionary criteria included the presence of cardiac disease or claudication in the legs, which limits exercise capacity. Measurement of the pulmonary function tests consisted of spirometry and a $\mathrm{CO}$ diffusion test. The demographics and pulmonary function tests of the patients are presented in Table 1. Each patient authorized their participation by signing an informed consent agreement. The protocol was approved by the ethics and research committees of our institution.

\section{Cardiopulmonary Exercise Test}

An incremental cardiopulmonary stress test, with an increase of the work load of 10-15 Watts every minute, was performed according to the American Thoracic Society/ American College of Chest Physicians regulations. ${ }^{3,4,7}$ A metabolic cart (Oxycon Pro, Erich Jaeger, Höchberg, Germany) was utilized. The reference values of Jones et al for $\dot{\mathrm{V}}_{\mathrm{O}_{2}}$, power $(\dot{\mathrm{W}}), \dot{\mathrm{V}}_{\mathrm{E}}$, and $\dot{\mathrm{V}}_{\mathrm{O}_{2}}$ /heart rate were used. ${ }^{8,9}$ Dyspnea and fatigue of the lower extremities were recorded according to the Borg scale. The study recorded maximum power $\left(\dot{\mathrm{W}}_{\text {max }}\right)$, maximum oxygen consumption $\left(\dot{\mathrm{V}}_{\mathrm{O}_{2}} \max \right)$, 


\section{Ventilatory Ineficiency as a Limiting Factor for Exercise in Patients With COPD}

Table 1. Demographic Characteristics and Functional Study at Rest $(n=35)$

\begin{tabular}{ll}
\hline \hline Age, y & $64 \pm 8.2$ \\
Sex, no. male/female & $24 / 11$ \\
BMI, kg/m ${ }^{2}$ & $26.7 \pm 4.4$ \\
FVC, $\%$ predicted & $86.9 \pm 19.1$ \\
$\mathrm{FEV}_{1}, \%$ predicted & $59.1 \pm 22.8$ \\
$\mathrm{FEV}_{1} / \mathrm{FVC}, \%$ & $59.4 \pm 14.4$ \\
$\mathrm{D}_{\mathrm{LCO}}, \%$ predicted & $52.5 \pm 12.6$ \\
$\mathrm{D}_{\mathrm{LCO}} /$ alveolar volume, $\%$ & $57 \pm 16.2$ \\
\hline \pm values are mean \pm SD. & \\
$\mathrm{BMI}=$ body mass index & \\
$\mathrm{D}_{\mathrm{LCO}}=$ diffusing capacity of the lung for carbon monoxide & \\
\hline
\end{tabular}

and the anaerobic threshold, according to the V-slope method. 3,7 The $\dot{\mathrm{V}}_{\mathrm{O}_{2}}$ measured at anaerobic threshold was represented as a percent-of-predicted $\dot{\mathrm{V}}_{\mathrm{O}_{2}} \max$.

The $\dot{\mathrm{V}}_{\mathrm{E}}$, breathing reserve (breathing reserve $=1-$ $\dot{\mathrm{V}}_{\text {Emax }}$ /predicted maximal voluntary ventilation) and the $\dot{\mathrm{V}}_{\mathrm{E}} / \dot{\mathrm{V}}_{\mathrm{CO}_{2}}$ determined at the anaerobic threshold were measured. $3,4,7,10,11$ The expiratory flow limitation was determined by superimposing the flow/volume dynamic curve over the maximum expiratory flow-volume curve, and was calculated at the final work load of the test, plotting the volume with flow overlap, over the tidal volume in the horizontal axis. The value of expiratory flow limitation was expressed as a percentage (Fig. 2A shows a subject without expiratory flow limitation and Fig. 2B shows the same subject with expiratory flow limitation at the final step of the exercise). In each work load a forced inspiratory capacity was determined, and the decrease ( $\Delta$ inspiratory capacity) was calculated by its difference between the beginning and the end of the exercise. ${ }^{12-15}$

As substitute parameters of cardiac function, the oxygen pulse $\left(\dot{\mathrm{V}}_{\mathrm{O}_{2}}\right.$ /heart rate) and the circulatory power were calculated at peak exercise. ${ }^{15-18}$ The $\dot{\mathrm{V}}_{\mathrm{O}_{2}}$ /heart rate is a surrogate for the systolic volume by the Fick equation: $\dot{\mathrm{V}}_{\mathrm{O}_{2}}=$ cardiac output $\times \Delta \mathrm{C}(\mathrm{a}-\mathrm{v}) \mathrm{O}_{2}$, and circulatory power $\left(\% \dot{\mathrm{V}}_{\mathrm{O}_{2}} \max \times\right.$ peak systolic blood pressure $)$ is a surrogate for cardiac power (cardiac output $X$ mean arterial pressure $\times \mathrm{K}){ }^{16-21}$

\section{Statistical Analysis}

Statistical descriptive analysis was performed using the Pearson coefficient of correlation for variables with a normal distribution. The normal distribution was verified with the Shapiro-Wilk test. The association between the independent continuous variable $\left(\dot{\mathrm{V}}_{\mathrm{E}} / \dot{\mathrm{V}}_{\mathrm{CO}_{2}}\right)$ and response continuous variables $\left(\dot{\mathrm{V}}_{\mathrm{O}_{2}}, \dot{\mathrm{W}}\right.$, anaerobic threshold, $\dot{\mathrm{V}}_{\mathrm{O}_{2}}$ /heart rate, and circulatory power) was assessed by bivariate linear regression.
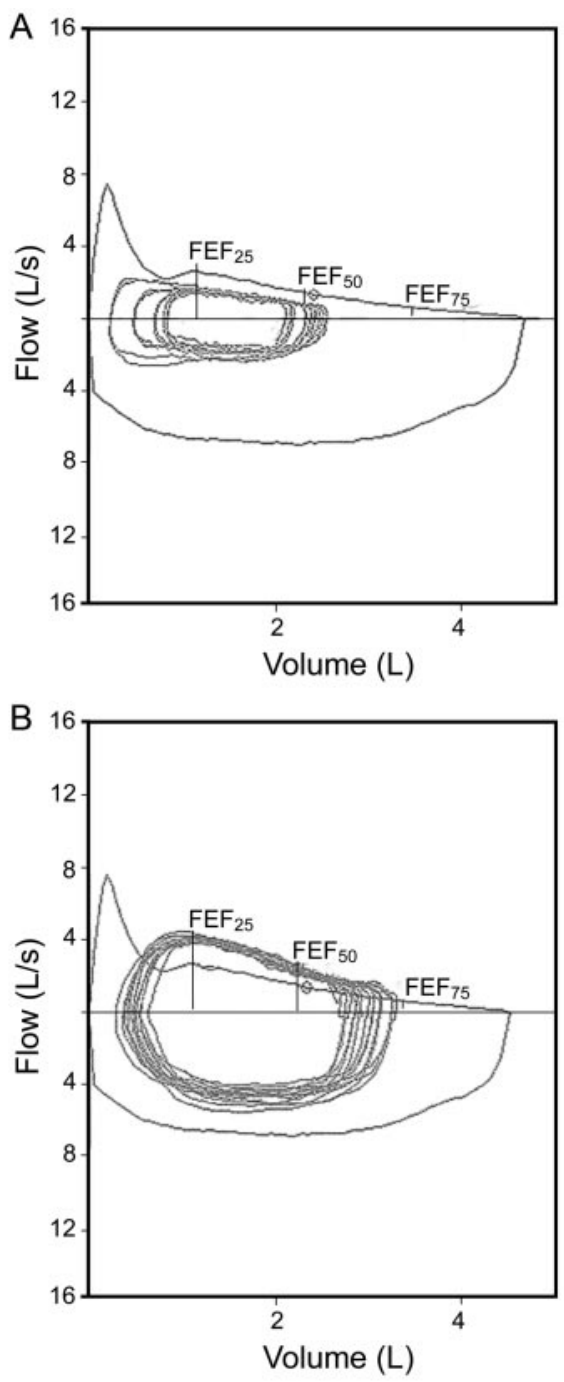

Fig. 2. A: Dynamic flow-volume curve superimposed on the maximum expiratory flow-volume curve: subject without expiratory flow limitation in the middle of the test. B: The same subject at the final step of the exercise: a $100 \%$ limitation of the expiratory flow is observed. $\mathrm{FEF}_{25}=$ forced expiratory flow at $25 \%$ of the expiratory maneuver.

We further constructed 5 multiple regression models analyzing the independent variables $\dot{\mathrm{V}}_{\mathrm{E}} / \dot{\mathrm{V}}_{\mathrm{CO}_{2}}$, age, body mass index, expiratory flow limitation, and dynamic hyperinflation, and their association over each of the following dependent continuous variables: $\dot{\mathrm{V}}_{\mathrm{O}_{2}}, \dot{\mathrm{W}}$, anaerobic threshold, $\dot{\mathrm{V}}_{\mathrm{O}_{2}}$ /heart rate, and circulatory power.

The relationship between dynamic hyperinflation and the parameters of interest were evaluated by a comparison of means through analysis of variance and subject to demonstration of a normal distribution in each group. Values of $P<.05$ (CI 95\%) were considered significant. Software was used (SPSS, version 18.0, SPSS, Chicago, Illinois). The sample size was calculated (EPIDAT 3.1, Dirección 


\section{Ventilatory Inefficiency as a Limiting Factor for Exercise in Patients With COPD}

Table 2. Results of Cardiopulmonary Stress Test

\begin{tabular}{|c|c|}
\hline Dyspnea, Borg score & $5 \pm 1.7$ \\
\hline Fatigue of extremities, Borg score & $4 \pm 1.6$ \\
\hline$\dot{\mathrm{V}}_{\mathrm{O}_{2}} \max , \%$ predicted & $75.2 \pm 20$ \\
\hline$\dot{\mathrm{W}}_{\max }^{2}, \%$ predicted & $68.6 \pm 23.3$ \\
\hline Anaerobic threshold, $\% \dot{\mathrm{V}}_{\mathrm{O}_{2}}$ max predicted & $50.5 \pm 16.9$ \\
\hline$\dot{\mathrm{V}}_{\text {Emax }}, \%$ predicted & $87 \pm 20.9$ \\
\hline Breathing reserve, $\%$ & $13.5 \pm 19.4$ \\
\hline Expiratory flow limitation, $\%$ & $75 \pm 25.3$ \\
\hline$\Delta$ Inspiratory capacity, $\mathrm{L}$ & $0.36 \pm 0.28$ \\
\hline$\dot{\mathrm{V}}_{\mathrm{E}} / \dot{\mathrm{V}}_{\mathrm{CO}_{2}}, \%$ & $35.9 \pm 5.6$ \\
\hline$\dot{\mathrm{V}}_{\mathrm{O}_{2}} /$ heart rate, $\%$ predicted & $91 \pm 16.8$ \\
\hline $\begin{array}{c}\text { Circulatory power, } \% \dot{\mathrm{V}}_{\mathrm{O}_{2}} \max \times \\
\text { peak systolic blood pressure }\end{array}$ & $12.765 \pm 4.164$ \\
\hline $\begin{array}{l}\text { Values are mean } \pm \mathrm{SD} \text {. } \\
\dot{\mathrm{V}}_{\mathrm{O}_{2}} \max =\text { maximum oxygen consumption } \\
\dot{\mathrm{W}}_{\max }=\text { maximum power } \\
\dot{\mathrm{V}}_{\mathrm{Emax}}=\text { maximum minute volume } \\
\dot{\mathrm{V}}_{\mathrm{O}_{2}} \text { /heart rate }=\text { oxygen pulse }\end{array}$ & \\
\hline
\end{tabular}

Xeral de Saúde Pública, A Coruña, Espana, http:// www.sergas.es).

\section{Results}

Thirty-five subjects with COPD were studied, including 24 men and 11 women, with a mean \pm SD age of $64 \pm 8.2 \mathrm{y}$ (range 49-80 y). All suffered from pulmonary emphysema, as demonstrated by axial computed tomography. They did not have a prior history of cardiopathy, and their electrocardiograms at rest did not demonstrate alterations. The demographic and functional characteristics are presented in Table 1.

The subjects finished the test secondary to dyspnea and leg fatigue (mean \pm SD Borg scale scores $5 \pm 1.7$ and $4 \pm 1.6$, respectively), with elevated levels of $\dot{V}_{\mathrm{E}}$ (mean $\pm \mathrm{SD} 87 \pm 20.9 \%$ of the maximum predicted value), and accentuated decreases in breathing reserve (mean \pm SD $13.5 \pm 19.4 \%$ ). They presented a decrease in $\dot{\mathrm{W}}_{\max }$ and in the $\dot{\mathrm{V}}_{\mathrm{O}_{2}}$ max. A severe increase in $\dot{\mathrm{V}}_{\mathrm{E}} / \dot{\mathrm{V}}_{\mathrm{CO}_{2}}$ was demonstrated (mean \pm SD $35.9 \pm 5.6$ ), along with severe expiratory flow limitation (mean \pm SD $75 \pm 25.3 \%$ ). Twentyeight subjects presented dynamic hyperinflation. The mean \pm SD $\Delta$ inspiratory capacity was $360 \pm 280 \mathrm{~mL}$. The results of the cardiopulmonary stress tests are presented in Table 2.

It was suggested by linear regression that $\dot{\mathrm{V}}_{\mathrm{E}} / \dot{\mathrm{V}}_{\mathrm{CO}_{2}}$ may translate into an exercise limitation. Each unit of increase in $\dot{\mathrm{V}}_{\mathrm{E}} / \dot{\mathrm{V}}_{\mathrm{CO}_{2}}$ decreased $\dot{\mathrm{V}}_{\mathrm{O}_{2}} \max$ by $2.0 \%(95 \% \mathrm{CI}-3$ to -0.9 ), reduced $\dot{\mathrm{W}}_{\max }$ by $2.6 \%$ (95\% CI -3.8 to -1.4$)$, and decreased anaerobic threshold by $1.6 \%(95 \% \mathrm{CI}-2.6$ to -0.67$)(P<.001, P<.001$, and $P=.003$, respectively), as shown in Table 3 and Figure 3. In relation to
Table 3. Influence of Ventilatory Inefficiency Over the Evaluated Parameters

\begin{tabular}{|c|c|c|}
\hline & $\dot{\mathrm{V}}_{\mathrm{E}} / \dot{\mathrm{V}}_{\mathrm{CO}_{2}}$ & $P$ \\
\hline$\dot{\mathrm{V}}_{\mathrm{O}_{2}} \max , \%$ of reduction* & $-2.0(-3$ to -0.9$)$ & $<.001$ \\
\hline$\dot{\mathrm{W}}_{\max }, \%$ of reduction* & $-2.6(-3.8$ to -1.4$)$ & $<.00$ \\
\hline Anaerobic threshold, $\%$ of reduction* & $-1.6(-2.6$ to -0.67$)$ & .00 \\
\hline$\dot{\mathrm{V}}_{\mathrm{O}_{2}}$ /heart rate, $\%$ of reduction $*$ & $-1.0(-2.1$ to 0$)$ & .04 \\
\hline $\begin{array}{r}\text { Circulatory power, } \% \dot{\mathrm{V}}_{\mathrm{O}_{2}} \max \times \\
\text { peak systolic blood pressure } \dagger\end{array}$ & $-322.7(-594$ to -51$)$ & .02 \\
\hline \multicolumn{3}{|c|}{$\begin{array}{l}\text { * Represented as a percentage of reduction per unit of the ratio of minute volume }\left(\dot{\mathrm{V}}_{\mathrm{E}}\right) \text { to } \\
\mathrm{CO}_{2} \text { production }\left(\dot{\mathrm{V}}_{\mathrm{CO}_{2}}\right) \\
\dagger \text { Represented as a reduction in absolute values per unit of } \dot{\mathrm{V}}_{\mathrm{E}} / \dot{\mathrm{V}}_{\mathrm{CO}_{2}} . \\
\mathrm{V}_{\mathrm{O}_{2}} \max =\text { maximum oxygen consumption } \\
\mathrm{W}_{\max }=\text { maximum power } \\
\dot{\mathrm{V}}_{\mathrm{O}_{2}} \text { /heart rate }=\text { oxygen pulse }\end{array}$} \\
\hline
\end{tabular}

cardiocirculatory parameters, $\dot{\mathrm{V}}_{\mathrm{E}} / \dot{\mathrm{V}}_{\mathrm{CO}_{2}}$ reduced $\dot{\mathrm{V}}_{\mathrm{O}_{2}}$ /heart rate by $1 \%(95 \% \mathrm{CI}-2.1$ to 0$)$ and reduced circulatory power by 322.7 units (95\% CI -594 to -51 ) for each unit of increase in $\dot{\mathrm{V}}_{\mathrm{E}} / \dot{\mathrm{V}}_{\mathrm{CO}_{2}}(P=.049$ and $P=.02$, respectively).

In the multiple regression analysis none of the models independently associated with the response continuous variables $\left(\dot{\mathrm{V}}_{\mathrm{O}_{2}}, \dot{\mathrm{W}}\right.$, anaerobic threshold, $\dot{\mathrm{V}}_{\mathrm{O}_{2}}$ /heart rate, and circulatory power) were significant, meaning that the relation between $\dot{\mathrm{V}}_{\mathrm{E}} / \dot{\mathrm{V}}_{\mathrm{CO}_{2}}$ was confounded by differences in age, body mass index, expiratory flow limitation, and dynamic hyperinflation.

\section{Effect of Dynamic Hyperinflation}

The mean $\pm \mathrm{SD} \dot{\mathrm{V}}_{\mathrm{O}_{2}}$ max was $75.2 \pm 20 \%$; in the 7 subjects without dynamic hyperinflation, it reached $93.4 \pm 17.1 \%$, and it decreased to $70.7 \pm 18.2 \%$ in the 28 subjects with dynamic hyperinflation $(P=.005)$ (Fig. 4A). The mean $\pm \mathrm{SD} \dot{\mathrm{W}}_{\max }$ was $68.6 \pm 23.3 \%$; in the 7 subjects without dynamic hyperinflation it reached $87 \pm 18.5 \%$, and it decreased to $64 \pm 22.3 \%$ in the 28 subjects with dynamic hyperinflation $(P=.02)$ (see Fig. 4B).

\section{Discussion}

In our studied subjects with various degrees of COPD, the exercise test ended due to dyspnea and leg fatigue. ${ }^{19,20}$ They used a large part of their breathing reserves and presented a severe increase of $\dot{\mathrm{V}}_{\mathrm{E}} / \dot{\mathrm{V}}_{\mathrm{CO}_{2}}$ measured at anaerobic threshold, which is indicative of ventilatory inefficiency. In association they also presented an accentuated limitation in expiratory flow, and the majority had dynamic hyperinflation. An inverse relationship between $\dot{V}_{\mathrm{E}} /$ $\dot{\mathrm{V}}_{\mathrm{CO}_{2}}$ and a decrease in $\dot{\mathrm{V}}_{\mathrm{O}_{2}}$ max and in $\dot{\mathrm{W}}$ suggest participation of this mechanism in limiting exercise capacity in COPD patients. ${ }^{18,19,21,22}$ 

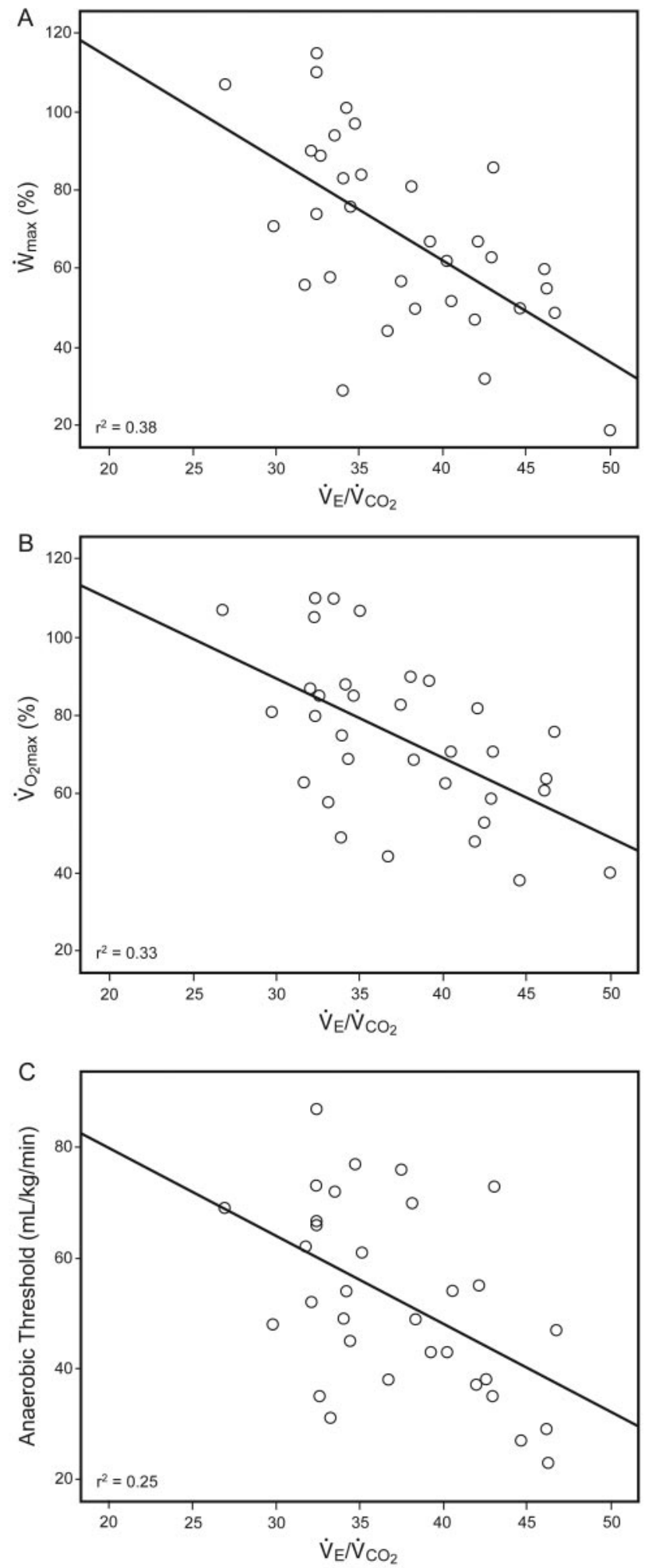

Fig. 3. A: Statistical correlation between maximal power $\left(\dot{\mathrm{W}}_{\max }\right)$ and the ratio of minute ventilation $\left(\dot{V}_{E}\right)$ to carbon dioxide production $\left(\dot{\mathrm{V}}_{\mathrm{CO}_{2}}\right)$. B: Statistical correlation between maximal oxygen consumption $\left(\dot{\mathrm{V}}_{\mathrm{O}_{2}}\right.$ max) and $\dot{\mathrm{V}}_{\mathrm{E}} / \dot{\mathrm{V}}_{\mathrm{CO}_{2}}$. C: Statistical correlation between anaerobic threshold and $\dot{\mathrm{V}}_{\mathrm{E}} / \dot{\mathrm{V}}_{\mathrm{CO}_{2}}$.

\section{Role of Ventilatory Inefficiency in Limiting Exercise}

Ventilatory inefficiency is a multi-dependent parameter that represents an increase in the physiological dead space and early lactic acidosis (due to a deficit between $\mathrm{O}_{2}$ muscle transport and requirement). Ventilatory inefficiency also involves deregulation of central and peripheral respiratory control and an augment in ergoreceptor activity, factors that are present in COPD. ${ }^{19-22}$ On the other side, expiratory flow limitation during respiration causes dynamic hyperinflation and enhances respiratory work. This behavior increases when the closing volume exceeds the residual functional capacity, until expiratory flow limitation and dynamic hyperinflation develop. ${ }^{12-15,19,23-25}$

In healthy young subjects the mean $\dot{\mathrm{V}}_{\mathrm{E}} / \dot{\mathrm{V}}_{\mathrm{CO}_{2}}$ is about 25 , and near 30 in older individuals. Usually it is less than 32 at or near the anaerobic threshold. Values over 34 are considered ventilatory inefficiency. ${ }^{3,4,26-28}$ Ventilatory inefficiency enhances the ventilatory requirement, which, when associated with an increase in expiratory resistance, impedes deflation and enhances dynamic hyperinflation. ${ }^{12,13,19-21,23,24}$ During exercise there is a strong evidence of the limitation imposed by dynamic hyperinflation, a situation that has also been demonstrated in daily activities and in the 6-min walk test.23,24 Dynamic hyperinflation is one of the main determinants of exercise limitation, and is commonly measured as $\Delta$ inspiratory capacity, as was performed in our study. ${ }^{23-25}$

In this regard, we postulated that ventilatory inefficiency may be an independent contribution to pathophysiologic understanding of exercise limitation in COPD. In particular, $\dot{\mathrm{V}}_{\mathrm{E}} / \dot{\mathrm{V}}_{\mathrm{CO}_{2}}$ is an independent indicator of a negative prognosis in other diseases such as congestive heart failure. ${ }^{10,11,22}$ In this study we have shown that ventilatory inefficiency, represented by $\dot{\mathrm{V}}_{\mathrm{E}} / \dot{\mathrm{V}}_{\mathrm{CO}_{2}}$, may increase ventilatory demand and dynamic hyperinflation, which translates into a limitation of functional capacity in COPD patients, reducing $\dot{\mathrm{V}}_{\mathrm{O}_{2}} \max$ and power (see Table 3).

\section{Ventilatory Inefficiency and Deterioration of the Surrogate Parameters of Cardiocirculatory Function}

The right ventricle is sensitive to afterload changes, which is a relevant factor in COPD, where dynamic hyperinflation increases the impedance of the right ventricle by decreasing the vascular compliance due to alveolar pressure. ${ }^{26-32}$ Our observations allow us to postulate that ventilatory inefficiency may deteriorate systolic volume of these patients (represented by $\dot{\mathrm{V}}_{\mathrm{O}_{2}}$ /heart rate), possibly enhancing expiratory flow limitation and dynamic hyperinflation. ${ }^{32,33}$

Cardiac power (cardiac output $\times$ mean arterial pressure $\times K$ ) represents the flow generated by the heart and the perfusion pressure that it sustains. Because $\dot{\mathrm{V}}_{\mathrm{O}_{2}}$ max in- 

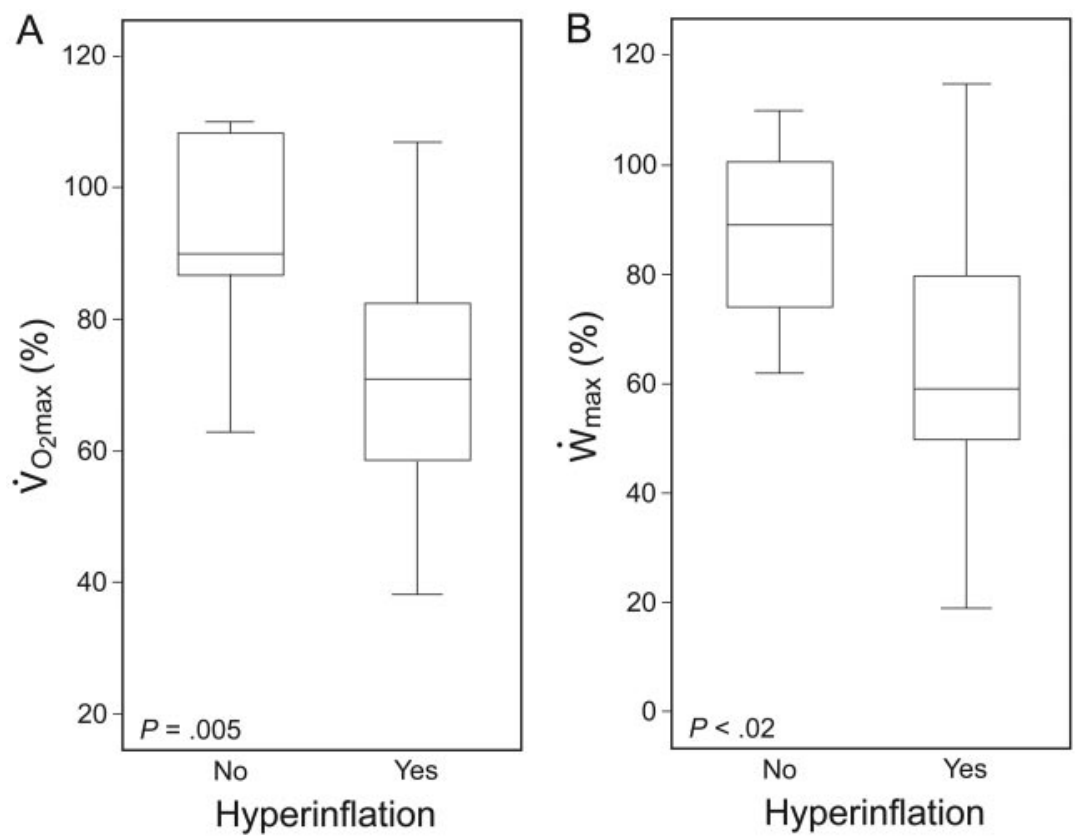

Fig. 4. A: Descriptive statistics of maximal oxygen consumption $\left(\dot{\mathrm{V}}_{\mathrm{O}_{2}} \max \right)$ in patients with and without dynamic hyperinflation. B: Descriptive statistics of maximal power $\left(\dot{W}_{\text {max }}\right)$ in subjects with and without dynamic hyperinflation.

creases linearly, it is postulated that circulatory power (circulatory power $=\% \dot{\mathrm{V}}_{\mathrm{O}_{2}} \max \times$ peak systolic blood pressure) adequately represents this parameter. To detect the influence of ventilatory inefficiency over cardiac power, we used circulatory power, which has not previously been evaluated in conjunction with COPD. ${ }^{34-37}$ Our results showed a reduction in circulatory power related with ventilatory inefficiency. To the best of our knowledge this is the first study to describe a reduction of cardiocirculatory function, through surrogate parameters of systolic volume and cardiac power, due to a ventilatory inefficiency.

A limitation to our study is the small number of subjects. We believe the increased ventilatory demand caused by ventilatory inefficiency, potentiating dynamic hyperinflation, might be bigger in patients with advanced COPD. We think that studies with higher numbers of COPD subjects, stratified by their severity degree, will support this hypothesis. On the other hand, the influence of ventilatory inefficiency on the prognosis of COPD patients deserves to be demonstrated.

\section{Conclusions}

The strength of this study is that it suggests that ventilatory inefficiency, which manifests itself as an abnormal increase of $\dot{\mathrm{V}}_{\mathrm{E}} / \dot{\mathrm{V}}_{\mathrm{CO}_{2}}$, may have implications in the deterioration of the exercise capacity of patients with COPD as an independent parameter. The inclusion of this parameter in the study of these patients may mean a contribution toward the understanding of its physiopathology. Upon evaluating the surrogate parameters of cardiocirculatory function, we showed that $\dot{\mathrm{V}}_{\mathrm{E}} / \dot{\mathrm{V}}_{\mathrm{CO}_{2}}$ detrimentally influences this function. We consider a weakness of our study the limited number of subjects. Randomized clinical controlled trials with a greater number of subjects and a better stratification of the degrees of COPD are needed to consider ventilatory inefficiency's influence over the exercise capacity in COPD.

\section{ACKNOWLEDGMENTS}

The authors thank Sebastián Fernández-Bussy MD, Chief of Interventional Pneumology, Clínica Alemana de Santiago, Facultad de Medicina Clínica Alemana, Universidad del Desarrollo, Santiago, Chile, for reviewing the manuscript.

\section{REFERENCES}

1. Calverley PM, Koulouris NG. Flow limitation and dynamic hyperinflation: key concepts in modern respiratory physiology. Eur Respir J 2005;25(1):186-199.

2. Ranieri VM, Dambroso M, Brienza N. Intrinsic PEEP and cardiopulmonary interaction in patients with COPD and acute ventilatory failure. Eur Respir J 1996;9(6):1283-1292.

3. Weisman IM, Beck KC, Casaburi R, Cotes JE, Crapo RO, Dempsey JA, et al. American Thoracic Society/American College of Chest Physicians. ATS/ACCP statement on cardiopulmonary exercise test. Am J Respir Crit Care Med 2003;167(2):211-277.

4. Palange P, Ward SA, Carlsen KH, Casaburi R, Gallagher CG, Gosselink R, et al; ERS task force. Recommendations on the use of exercise testing in clinical practice. Eur Respir J 2007;29(1):185209. 


\section{Ventilatory Inefficiency as a Limiting Factor for Exercise in Patients With COPD}

5. Calverley PM. The GOLD classification has advanced understanding of COPD (editorial). Am J Respir Crit Care Med 2004;170(3):211214.

6. Foster WL, Pratt PC, Roggli VL, Godwin JD, Halvorsen RA, Putman CE. Centrilobular emphysema: CT - pathologic correlation. Radiology 1986;159(1):27-32.

7. Wasserman K. Diagnosing cardiovascular and lung pathophysiology from exercise gas Exchange. Chest 1997;112(4):1091-1101.

8. Jones NL, Makrides L, Hitchcock C, Chypchar T, McCartney N, et al. Normal standards for an incremental progressive cycle ergometer test. Am Rev Respir Dis 1985;131(5):700-708.

9. Jones NL, Summers E, Killian KJ. Influence of age and stature on exercise capacity during incremental cycle ergometry in men and women. Am Rev Respir Dis 1989;140(5):1373-80.

10. Tumminello G, Guazzi M, Lancellotti P, Pierard LA. Exercise ventilation inefficiency in hearth failure: pathophysiological and clinical significance. Eur Heart J 2007;28(6):673-678.

11. Gitt AK, Wassermann K, Kilowski C, Kleemann T, Kilkowski A, Bangert $\mathrm{M}$, et al. Exercise anaerobic threshold and ventilatory efficiency identify heart failure patients for high risk of early death. Circulation 2002;106(24):3079-3084.

12. Johnson B, Weisman IM, Zeballos J, Beck K. Emerging concepts in the evaluation of ventilatory limitation during exercise. The exercise tidal flow-volume loop. Chest 1999;116(2):488-503.

13. O'Donnell DE, Webb KA. Exertional breathlessness in patients with chronic airflow limitation: the role of lung hyperinflation. Am Rev Respir Dis 1993;148(5):1351-1357.

14. O'Donnell DE, Chau LK, Bertrley JC, Webb K. Qualitative aspects of exertional breathlessness in chronic airflow limitation: pathophysiologic mechanisms. Am J Respir Crit Care Med 1997;155(1):109115 .

15. O'Donnell DE, Revill SM, Webb KA. Dynamic hyperinflation and exercise intolerance in chronic obstructive pulmonary disease. Am J Respir Crit Care Med 2001;164(5):770-777.

16. Fleg JL, Piña IL, Balady GJ, Chaitman B, Fletcher B, Lavie C, et al. Assessment of functional capacity in clinical and research applications. An advisory from the committee on exercise, rehabilitation, and prevention, council on clinical cardiology, American Hearth Association. Circulation 2000;102(13):1591-1597.

17. Nicholls DP, O'Dochartaigh C, Riley MS. Circulatory power, a new perspective on an old friend. Eur Heart J 2002;23(16):1242-45.

18. Jones NL, Killian KJ. Mechanisms of disease: exercise limitation in health and disease. N Engl J Med 2000;343(9):632-641.

19. Baril J, De Souza M, Leroy D, Aguilaniu B, Glady C, Olivenstein R, et al. Does dynamic hyperinflation impair submaximal exercise cardiac output in chronic obstructive pulmonary disease? Clin Invest Med 2006;29(2):104-109.

20. Richardson RS, Leek BT, Gavin TP, Haseler LJ, Mudaliar SRD, Henry R, et al. Reduced mechanical efficiency in chronic obstructive pulmonary disease but normal peak $\mathrm{VO}_{2}$ with small muscle mass exercise. Am J Respir Crit Care Med 2004;169(1):89-96.

21. Pinto Plata V, Celli-Cruz R, Vassaux C, Torre-Bouscoulet L, Mendes A, Rassulo J, et al. Differences in cardiopulmonary exercise test results by American Thoracic Society/European Respiratory Society global initiative for chronic obstructive lung disease stage categories and gender. Chest 2007;132(4):1204-1211.

22. Mejhert M, Linder-Klingsell E, Edner M, Kahan T, Persson H. Ventilatory variables are strong prognostic markers in elderly patients with hearth failure. Heart 2002;88(3):239-243.
23. Callens E, Graba S, Gillet-Juvin K, Essalhi M, Bidaud-Chevalier B, Peiffer $\mathrm{C}$, et al. Measurement of Dynamic hyperinflation after a 6 minute walk test in patients with COPD. Chest 2009;136(6):1466-1472.

24. Hannink JD, Van Helvoort HA, Dekhuijzen PN, Heijdra YF. Dynamic hyperinflation during daily activities: does COPD global initiative for chronic obstructive lung disease stage matter? Chest 2010; 137(5):1116-1121.

25. Casanova C, Cote C, De Torres JP, Aguirre-Jaime A, Marin JM, Pinto-Plata V. Inspiratory to total lung capacity ratio predicts mortality in patients with chronic obstructive pulmonary disease. Am J Respir Crit Care Med 2005;171(6):591-597.

26. Kleber FX, Waurick P, Winterhalter M. CPET in hearth failure. Eur Heart J 2004;6(suppl D):D1-D4 .

27. Ponikowski P, Francis DP, Piepoli MF, Davies LC, Chua TP, Davos $\mathrm{CH}$, et al. Enhanced ventilatory response to exercise in patients with chronic hearth failure and preserved exercise tolerance. Marker of abnormal cardiorespiratory reflex control and predictor of poor prognosis. Circulation 2001;103(7):967-972.

28. Ribeiro JP, Stein R, Chiappa GR. Beyond peak oxygen uptake: new prognostic markers from gas exchange exercise tests in chronic heart failure. J Cardiopulm Rehabil 2006;26(2):63-71.

29. Matthay RA, Arroliga AC, Wiedemann HP, Schulman DS, Mahler DA, et al. Right ventricular function at rest and during exercise in chronic obstructive pulmonary disease. Chest 1992;5:(Suppl):255S262S.

30. Wright JL, Levy RD, Churg A. Pulmonary hypertension in chronic obstructive pulmonary disease: current theories of pathogenesis and their implications for treatment. Thorax 2005;60(7):605-609.

31. Haddad F, Hunt SA, Rosenthal DN, Murphy DJ. Right ventricular function in cardiovascular disease, part I. Anatomy, Physiology, aging, and functional assessment of the right ventricle. Circulation 2008;117(11):1436-1448.

32. Haddad F, Doyle R, Murphy DJ Hunt SA. Right ventricular function in cardiovascular disease, part II. Pathophysiology, clinical importance, and management of right ventricular failure. Circulation 2008; 117(13):1717-1731.

33. Vassaux C, Torre-Bouscoulet L, Zeineldine S, Cortopassi F, PazDiaz H, Celli BR, et al. Effects of hyperinflation on the oxygen pulse as a marker of cardiac performance in COPD. Eur Respir J 2008; 32(5):1275-1282.

34. A. Cohen-Solal A, Tabet JY, Logeart D, Bourgoin P, Tokmakova M, Dahan M. A non-invasively determined surrogate of cardiac power ('circulatory power') at peak exercise is a powerful prognostic factor in chronic heart failure. Eur Heart $\mathbf{J}$ 2002;23(10): 806-814.

35. Scharf C, Merz T, Kiowski W, Oechslin E, Schalcher C, Brunner La Roca HP. Noninvasive assessment of cardiac pumping capacity during exercise predicts prognosis in patients with congestive heart failure. Chest 2002;122(4):1333-1339.

36. Williams SG, Jackson M, Ng LL, Barker D, Patwala A, Tan LB. Exercise duration and peak systolic blood pressure are predictive of mortality in ambulatory patients with mild-moderate chronic heart failure. Cardiology 2005;104(4):221-226.

37. Williams SG, Cooke GA, Wright DJ, Parsons WJ, Riley RL, Marshall $\mathrm{P}$, et al. Peak exercise cardiac power output. A direct indicator of cardiac function strongly predictive of prognosis in chronic hearth failure. Eur Heart J 2001;22(16):1496-1503. 